\title{
Gender Incongruence is No Longer a Mental Disorder
}

\author{
M. Fernández Rodríguez ${ }^{1,2 *}$, M. Menéndez Granda ${ }^{3}$, Villaverde González ${ }^{4}$ \\ 'Mental Health Center I "La Magdalena" University Hospital San Agustín de Avilés. Health Area III, Asturias, Spain \\ ${ }^{2}$ Gender Identity Treatment Unit of Principality of Asturias (UTIGPA), Spain \\ ${ }^{3}$ Master of General Health Psychology, University of Oviedo, Asturias, Spain \\ ${ }^{4}$ Intern Resident Psychologist, University Hospital San Agustín Avilés. Health Area III Asturias, Spain
}

Article Info

\section{Article Notes}

Received: July 30, 2018

Accepted: September 18, 2018

\section{${ }^{*}$ Correspondence:}

Dr. María Fernández Rodríguez, Centro de Salud Mental I "La Magdalena”. Valdés Salas, 4, 33400 Avilés, Asturias, Spain; Email: maria.fernandezr@sespa.es.

(c) 2018 Rodríguez MF. This article is distributed under the terms of the Creative Commons Attribution 4.0 International License.

\section{Keywords}

Gender identity

Gender dysphoria

Transsexualism

International Classification of Diseases (ICD-11)

International diagnostic classifications

\section{ABSTRACT}

The aim of this article is to highlight the historical path of transsexualism diagnosis since its inclusion to its elimination from the catalogue of mental disorders. We analyse the terminological changes that may account for this phenomenon in order to depathologise and just as the controversies raised by its location in the new Manual of International Statistical Classification of Diseases and Related Health Problems ICD-11.

ICD-11 drives out the term "Transsexualism" and replaces it with the term "Gender Incongruence" (GI). This new terminology will no longer be part of the chapter on mental disorders (Chapter 6) but a new chapter (Chapter 17) entitled "Conditions relating to sexual health" is created. These changes of ICD11 represent a breakthrough and a great sense of freedom for trans people, since WHO has included the different variants of gender in normality by not being considered a mental disorder.

The aim of this paper is to highlight the historical development of the diagnosis of transsexualism from its inclusion to the elimination of the chapter of mental disorders. Terminological changes that can best reflect this phenomenon to depathologize and the controversies raised by its location in the new manual of ICD-11 are analyzed.

Transsexualism, gender identity disorder or gender dysphoria, since was included in the international diagnostic classifications was (ICD- $9^{1}$, ICD-10 $10^{2}$ ) and is part of the chapter on mental disorders (DSM-5 ${ }^{3}$ ).

The diagnosis of transsexualism debuts in the International Classification of Diseases and Related Health Problems in 1978 (ICD-9)1. It was included in the section named "Sexual deviations and disorders", within neurotic disorders, personality disorders and other non-psychotic mental disorders. Therefore, it was at the same level as paraphilias and sexual deviations. In 1992, the $10^{\text {th }}$ revision of the International Classification of Diseases (ICD-10) ${ }^{2}$ entered into force. Unlike the ICD- ${ }^{1}$, gender identity disorders are an independent group of disorders of sexual inclination and sexual dysfunctions, although they continue to be included in adult personality and behaviour disorders (F60-F69) ${ }^{4}$.

On June 18, 2018 the World Health Organization (WHO) establish itself as a pioneer in the process of depathologization of transsexuality. This struggle, in order to stop transsexuality from being considered a mental disorder and to eliminate the gender identity disorder of the international manuals of mental disorders, had been represented in the last decade by the powerful movements 
of depathologization (Stop Trans Pathologization, depsychopathologisation statement released, etc) ${ }^{6,7,8}$.

The Manual of International Statistical Classification of Diseases and Related Health Problems (ICD-11) eliminates the term "transsexualism" and replaces it with the term "Gender Incongruence" (GI) 9 . This new terminology will no longer be part of the chapter on mental disorders (chapter 6) but a new chapter is created (chapter 17) called "conditions related to sexual health". These ICD-11 changes implied an advance and a great liberation for trans people who were doubly stigmatized since transsexuality has always been located around paraphilias and within personality disorders. Even so, the "gender incongruence" continues to be part of this manual that encompasses all diseases.

The name itself "Conditions related to sexual health" again creates confusion between the two realities sex/ gender. Sex refers to the biological characteristics of a person (male or female of the human being) while gender is a sociocultural construction that involves psychological aspects (identity) ${ }^{10}$. In the general heading, ICD-11 refers exclusively to sex and not to gender. This ambiguity may be due to the fact that this chapter, in addition to including gender incongruence, also contemplates sexual dysfunctions, which until now have also been considered mental disorders.

The terminology "Gender incongruence" is not something new, it was previously contemplated by the American Psychiatric Association when on February $10^{\text {th }}, 2010$ presented the draft of the fifth version of the Diagnostic and Statistical Manual of Mental Disorders $(\mathrm{DSM}-5)^{4}$. In an attempt to depathologize, it proposed the replacement of "Gender Identity Disorder" with "GI" (Gender Incongruence). This first draft didn't meet the expectations of the trans people that harbored the hope that transsexuality would disappear from the international diagnostic classifications just like it happened with homosexuality ${ }^{11}$. The DSM-5 ${ }^{3}$ concludes with the substitution of the term "Gender Identity Disorder" by "Gender Dysphoria" that continues to belong to the chapter on mental disorders.

Although the term GI didn't crystallize as a diagnosis, the DSM-5 puts emphasis on gender dysphoria both for defining gender dysphoria: "distress that may accompany the incongruence between felt or expressed gender and the gender assigned" and for describe the diagnostic criteria: "a marked incongruence between the felt gender and the primary and/or secondary sexual characteristics (or in young adolescents, the anticipation of secondary sexual characteristics)".

For its part, the ICD 11 continues defining the GI as "a marked and persistent incongruence between the gender felt or experienced and the gender assigned to birth"12. This incongruity is manifested in at least two of the following criteria:

- Strong dislike or disagreement with primary or secondary sexual characteristics due to incongruence with the experienced gender.

- Strong desire to get rid of some of those sexual characteristics due to the incongruence with the experienced gender.

- Strong desire to have the primary or secondary sexual characteristics of the experienced gender.

- Strong desire to be treated and accepted as a person of the felt gender.

Compare to the DSM-5, the ICD-11 replaces the state of distress associated with that incongruence by the terms dislike or discomfort with less psychopathological connotations. In addition, only two diagnostic criteria must be met. This diagnosis could, therefore, be fulfilled without wanting to get rid of the primary and secondary sexual characteristics of the felt gender. Feeling dislike with the primary or secondary sexual characteristics, along with the desire to be treated and accepted as a person of the felt gender, would be sufficient to make the diagnosis of GI and would not imply the desire to undergo medical-surgical interventions to achieve a gender confirmation.

In the ICD-11 we find two specifiers: changes in the anatomy of the female genitals and changes in the anatomy of the male genitals. In the former, it includes eliminating the breasts $(\mathrm{QF01.0})$ and eliminating the female genitals (QF01.10) and in the latter eliminating the male genitals (QF01.11). These changes would be codified in chapter 24, which refers to "Factors that influence health status or contact with health services", an existing chapter in ICD-10 (chapter 21). ICD-11 includes in this chapter the demands made by a person who may or may not be ill and who goes to health services for a specific purpose, such as receiving attention or limited service due to a current condition or when there is a circumstance or problem that influences a person's health status but is not in itself a current illness or injury.

The ICD-11, however, has not carried out the same process as homosexuality to completely depathologize transsexuality. GI continues to be part of a chapter of the manual and therefore of a diagnosis within sexual health ${ }^{13}$. On May 17, 1990 the WHO eliminated homosexuality from the chapter on mental disorders ${ }^{14}$ totally depathologizing the orientation of people without eliminating the right to health coverage through its inclusion in the section "other ICD-10 processes frequently associated with mental and behavioral alterations". Chapter XXI "factors influencing health status and contact with health services" include the Z 
codes "counseling related to sexual attitude, behaviour and orientation" (Z70) where some demands of homosexuals could be included ${ }^{2}$. The WHO justifies have taken gender incongruence out from mental illness, first of all, because at present there is greater normalization and knowledge about the diversity and gender variants that separate them from mental illness. Secondly, by eliminating this condition from the mental disorders chapter, the stigma which in our culture is more associated with mental disorders decreases ${ }^{12,15}$. Finally, WHO intend $s$ to justify the maintenance of this diagnosis by referring to the fact that, otherwise they would not be recipients of medical assistance interventions (harmonization and surgery) when they are demanded by these users. According to our point of view, this last argument, is possibly the least solid one since it could be questioned if we contemplate the possibility of including GI in other non-pathologizing processes that require medical-surgical interventions such as the assistance to pregnant women is considered ${ }^{16}$

Although there are some issues that still need to be clarified regarding the GO in the ICD new version, we must not lose sight of the most relevant fact. The WHO has included the different variants of gender in normality as they are not considered a mental illness.

To depathologize transsexuality and reach the same destination as homosexuality, the ICD-11 takes a broader journey. First of all, it replaces the diagnosis of "transsexualism" by "GI". Secondly, it no longer considers GI a mental disorder by eliminating it from the chapter on mental disorders. However, it makes an intermediate step by including GI in the chapter on sexual health.

After these reflections we will have to wait until 2019 when the ICD-11 will be presented in the World Health Assembly for adoption by the member states. This presentation will allow the different countries to plan how to use the new version, prepare the translations and train the health professionals until it comes into force in $2022^{5}$.

\section{References}

1. World Health Organization - WHO. Clasificación Internacional de Enfermedades. 9a ed. Ginebra: WHO, 1978. (trad. cast. Madrid: Meditor)

2. World Health Organization - WHO Clasificación Internacional de Enfermedades $10^{\mathrm{a}}$ ed. Ginebra: WHO, 1992. (trad. cast. Madrid: Meditor)

3. American Psychiatric Association. Diagnostic and statistical manual of mental disorders, $5^{\mathbf{a}}$ ed. Development, 2010. Recuperado en junio de 2012 de: http://dsm5.org

4. Fernández Rodríguez M. y Garcia-Vega E." Surgimiento, evolución y dificultades del diagnóstico de transexualismo" (Emergente, evolution and dificultéis of the transsexualism diagnosis). Rev.Asoc. Esp. de Neuropsiq., 2012; 32(113): 103-119. D.L. M. 17149-1981 ISSN: 0211-5735.

5. Christian Lindmeier (OMS) [Internet]. 18 Junio 2018. Centro de prensa Organización Mundial de la Salud. Available in: http://www. who.int/es/news-room/detail/17-06-2018-who-releases-newinternational-classification-of-diseases-(icd-11)

6. Suess A. La despatologización trans desde una perspectiva de derechos humanos. Ponencia presentada en Jornadas Feministas Estatales. Granada: Jornadas Feministas Estatales. 2009. Available in www.feministas.org/jornadas.html.

7. WPATH Board of Directors (2010). De-psychopathologisation statement released. (Citado en enero de 2012). Available in: https:// www.wpath.org/policies

8. Campaña Internacional Stop Trans Pathologization STP. (2013). Reflexiones de STP sobre el proceso de revisión de la CIE y la publicación del DSM-5. Available in: https://www.stp2012.info/ Comunicado_STP_agosto2013.pdf

9. World Health Organization-WHO Clasificación Internacional de Enfermedades $11 \mathrm{draft}$, 2018. Available in: https://icd.who.int/ browse11/l-m/en

10. Fernández Rodríguez M. "Sexo y género dos conceptos interdependientes". Mosaico № 49. Septiembre. 2011; ISSN: 18870600: 53-58. DL: B-16180-2005

11. Drescher J. Queer diagnoses: Parallels and contrasts in the history of homosexuality, gender variance, and the Diagnostic and Statistical Manual (DSM). Archives of Sexual Behavior. 2010; 39: 427-460.

12. Questions and answers WHO: changes in the classification of gender incongruence (transgender) in the new ICD-11. Geneva: World Health Organization; 2018.

13. Reed GM, Drescher J, Krueger RB, et al. Revising the ICD-10 Mental and Behavioural Disorders classification of sexuality and gender identity based on current scientific evidence, best clinical practices, and human rights considerations. World Psychiatry. 2016; 15: 205221.

14. World Health Organization [Internet]. 15 May 2015. LGBT health sees progress and challenges 15 years after homosexuality ceased being considered a disease. Available in: https://www.paho.org/hq/ index.php?option $=$ com_content\&view $=$ article\&id $=10964 \% 3$ A2015lgbt-health-sees-progress-and-challenges \&catid=740\%3Apressreleases\&Itemid $=1926 \&$ lang $=$ es

15. Drescher J, Cohen-Kettenis PT, Winter S. Minding the body: Situating gender diagnoses in the ICD-11. International Review of Psychiatry. 2012; 24(6): 568-577.

16. Cochran SD, Drescher J, Kismodi E, et al. Proposed declassification of disease categories related to sexual orientation in ICD-11: Rationale and evidence from the Working Group on Sexual Disorders and Sexual Health. Bulletin of the World Health Organization. 2014; 92: 672-679. 